\title{
A comparative study of the metabolic effort expended by horse riders during a jumping competition
}

\author{
J. A. Gutiérrez Rincón, J. Vives Turcó, I. Muro Martínez and I. Casas Vaqué \\ Generalitat de Catalunya, Secretaria General de l'Esport, Centre de Medicina de l'Esport de Barcelona, \\ Barcelona, Spain
}

\begin{abstract}
The three main Olympic horse riding disciplines are dressage, jumping, and three-day eventing (including dressage, cross country and jumping). In the jumping discipline (obstacle race), the 'team' (horse rider) is judged under the different conditions that might take place in a varied run. The horse is expected to show power and ability; the rider must show riding skill and good physical condition. However, the different conditions encountered by the rider during competition (duration of event, continuous isometric working level, especially in the inferior trunk, lead us to consider the need for a rider to develop different metabolic pathways to meet the high energy requirements of the competition.
\end{abstract}

Keywords: Horse riding, blood lactate, heart rate, horses

In the 'team' in the jumping events, energy output, like the physical effort of the rider, is related to technical riding ability.

\section{Materials and methods}

The study was undertaken using the following equipment: Cardiotachometer 'Sport-Tester' PE-3000 (Polar Electro, Oulu, Finland) with horse adaptor strap; Printerface PE-3000 (Polar Electro); Lactate 'Analox' Micro-stat P-LM4 (Analox, Hammersmith, UK); and blood sample collection material.

The study was carried out on three horses aged between 7 and 10 years, weighing between 350 and $500 \mathrm{~kg}$, and training for an average time of $4 \mathrm{~h} /$ week.

The riders trained for an average of $4 \mathrm{~h} /$ week, were of mean age 24.7 years, and mean weight $69.5 \mathrm{~kg}$. The information was collected in a social championship organized by the 'Club Hipic d'Osona' in Olost del Llusanés (Barcelona).

The test took place on a closed grass ground, $110 \times$ $60 \mathrm{~m}$, with varied jumps including 12 obstacles and one river making a total of 13 efforts with a maximum

Address for correspondence: Dr J. A. Gutiérrez Rincón, Generalitat De Catalunya, Secretaria General de l'Esport, Centre de Medicina de l'Esport de Barcelona, Passatge Permanyer 3, 08009-Barcelona, Spain

(C) 1992 Butterworth-Heinemann Ltd 0306-3674/92/010033-03 height of $1.20 \mathrm{~m}$ and a maximum width of $1.60 \mathrm{~m}$. Test duration was 45-60s.

The frequency of heart beat of both the riders and horses was registered by means of a tachometer before the competition, when they were warming up. Blood sampling took place 1, 3, 5 and 7 min after the competition, taken from the ears of the riders and from the upper gums of the horses. Lactate ion concentration was immediately analysed for all samples.

\section{Results and discussion}

The telemetric printouts of heart rates of horses and riders during the effort are shown in Figures 1 and 2. Lactate levels after effort in riders and horses are shown in Figure 3.

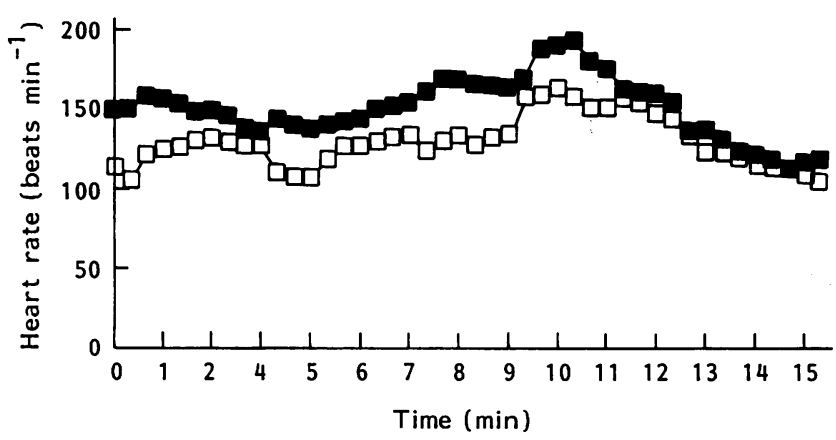

Figure 1. Heart rate of rider no. $1(\square)$ and horse no. 1 ( $\square$ ) before, during and after competition

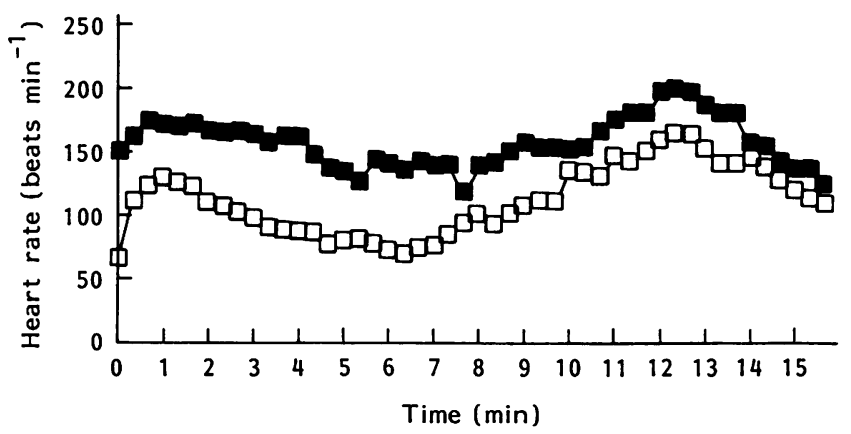

Figure 2. Heart rate of rider no. $2(\square)$ and horse no. 2 ( $\square$ ) before, during and after competition 
Metabolic effort expended by horse riders: J. A. Gutiérrez Rincón et al.
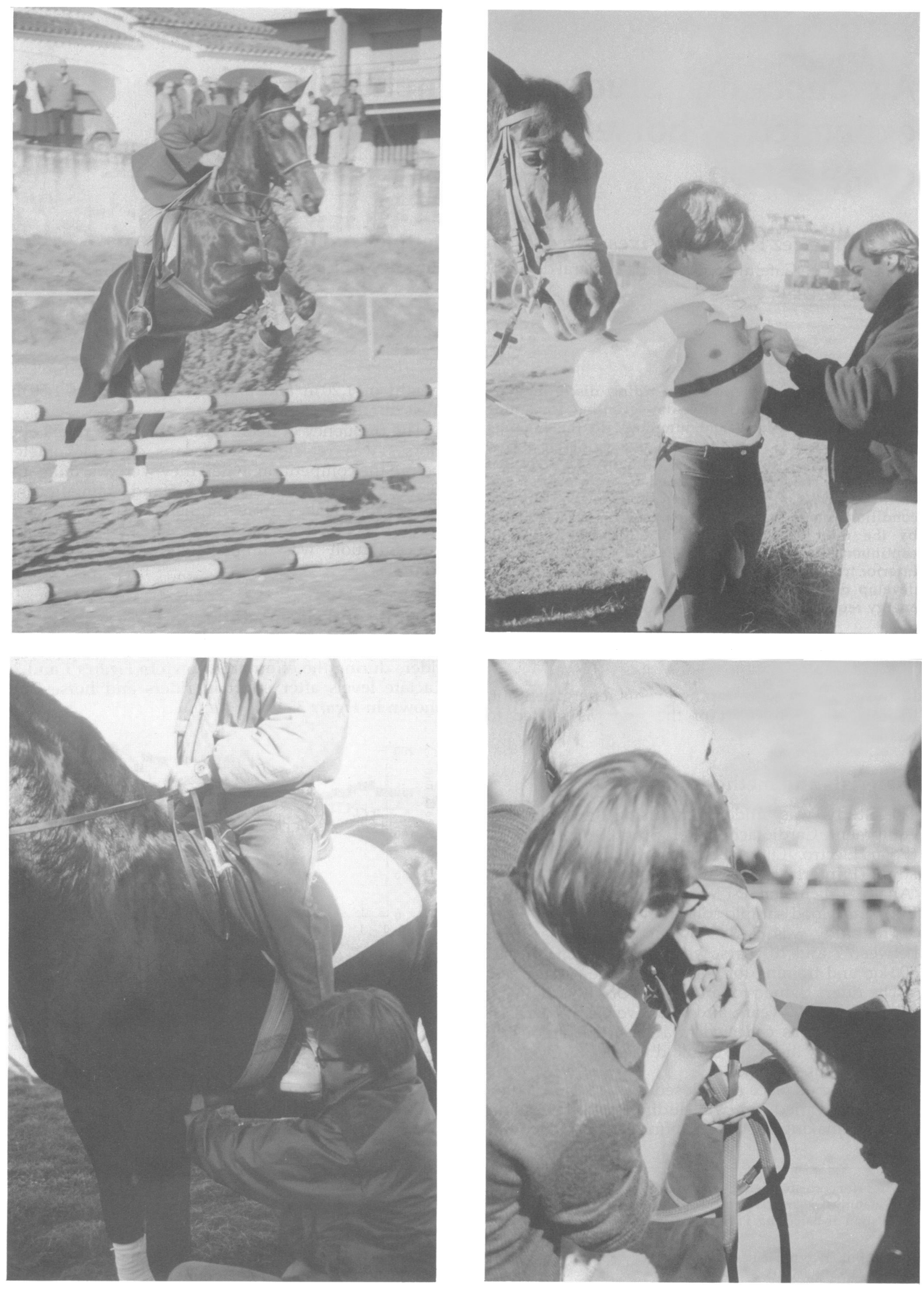

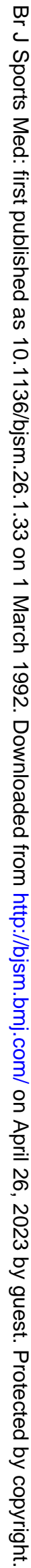




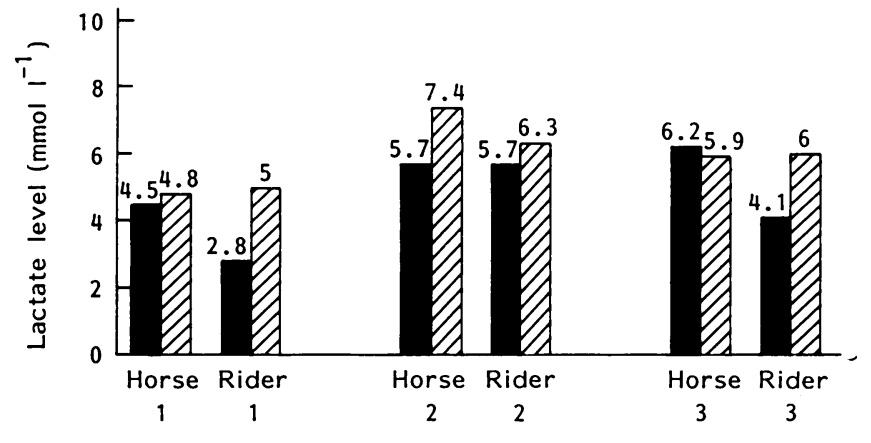

Figure 3. Levels of blood lactate in horses and riders $1 \mathrm{~min}$ $(\square)$ and 3 min ( $\square)$ after competition

The horses' heart rates are considerably increased, although the maximum registered values hardly reached $75 \%$ of the possible maximum of $230-240$ beats $/ \mathrm{min}^{1-6}$. However, when we observe heart rate in the riders, we see that their effort is $>90 \%$ of its maximum possible pulse rate. It seems that the rider effort during the jumping competition is higher than that of the horse.

The increased heart rate in the riders could be due to the tension they suffer because they know the risk possible in every jump. However, this is not corroborated by the lactate values after effort, which implies the involvement of the anaerobic pathway during the effort period (4-8 $\mathrm{mmol} / \mathrm{l})$. These levels are unchanged by nervous tension: they are a consequence of muscular activity. Higher lactate levels after exercise are seen on the riders' tests than on those of the horses. The accumulation of this metabolite is the same for both horses and riders 7,8 .

\section{Conclusions}

Energy expenditure during a jumping competition, as shown by pulse rate and blood lactate studies, is relatively higher in the rider than the horse.

\section{References}

1 Fregin GF, Thomas DP. Cardiovascular response to exercise in the horse. In: Snow DH, Persson SGB, Rose RJ, eds Equine Exercise Physiology. Cambridge: Granta Editions 1983: 76-90.

2 Gottlieb M, Essen-Gustavsson B, Lindholm A, Persson SGB. Circulatory and muscle metabolic responses to draught work compared to increasing trotting velocities. Equine Vet J 1988; 20: $430-4$.

3 Harris $\mathrm{P}$, Snow DH. The effects of high intensity exercise on the plasma concentration of lactate, potassium and other electrolytes. Equine Vet J 1988; 20: 109-13.

4 Huguet JM, Braun JP, Benard P et al. Sémiologie de la forme du cheval de sport dans les courses de vitesse. Rec Med Vet 1981; 157: 331-7.

5 Kraywanek $\mathrm{H}$. Lactic acid concentration and $\mathrm{pH}$ values in trotters after racing. I South Afr Vet Assoc 1974; 45: 355-60.

6 Lindholm A, Saltin B. The physiological and biochemical response of standard bred horses to exercise of varying speed and duration. Acta Vet Scand 1975; 15: 310-24.

7 Nimmo MA, Snow D. Changes in muscle glycogen, lactate and pyruvate concentrations in the thoroughbred horse following maximal exercise. In: Snow DH, Persson SGB, Rose RJ, eds. Equine Exercise Physiology. Cambridge: Granta Editions, 1983: 237-44.

8 Persson SGB. The significance of haematological data in the evaluation of soundness and fitness in the horse. In: Snow DH, Persson SGB, Rose RJ eds. Equine Exercise Physiology. Cambridge: Granta Editions, 1983: 324-7. 